\title{
Índices para avaliar o estado de nitrogênio da batata multiplicada por distintos materiais propagativos ${ }^{1}$
}

\author{
Marialva Alvarenga Moreira 2 , Paulo Cezar Rezende Fontes ${ }^{3}$, Paulo Roberto Cecon ${ }^{4}$, Roberto Fontes Araújo 5
}

\section{RESUMO}

Melhoria na eficiência de aplicação do $\mathrm{N}$ pode ser conseguida pela sincronização da demanda da planta com o suprimento de $\mathrm{N}$ durante o ciclo da batateira. O objetivo do trabalho foi determinar os valores ótimos de índices relacionados com o estado de nitrogênio ao longo do ciclo da batata cultivada em ambiente protegido, utilizando distintos materiais propagativos, tubérculo-semente, minitubérculo e broto, comuns na produção de tubérculo-semente básica. Os índices, determinados na quarta folha e na mais velha, foram intensidade da cor verde, avaliada pelo índice SPAD e pela tabela de cor, e características agronômicas: comprimento, largura, área e número de folíolos. Foram realizados três experimentos em vaso, em casa de vegetação na Universidade Federal de Viçosa. Em cada experimento, instalado no delineamento de blocos ao acaso, com quatro repetições, foram utilizadas seis doses de nitrogênio ( 0 ; 25; 50; 100; 200 e $400 \mathrm{mg} \mathrm{dm}^{-3}$ ). Os índices foram determinados a cada 10 dias iniciando-se aos 20 dias após a emergência. Com cada material de propagação, o índice SPAD medido tanto na QF quanto na FV respondeu de forma diferenciada ao incremento na dose de $\mathrm{N}$ e atingiu os valores ótimos de 41,3; 40,5; 37,0; 35,8; 36,0; 31,9 e 29,8 dos 20 aos 80 DAE, respectivamente, ao ser utilizado o tubérculo-semente básica. Com todos os materiais de propagação, a idade da planta influencia significativamente todas as variáveis, exceto o número de hastes ou o número de folhas, quando é utilizado broto ou minitubérculo, respectivamente. O valor ótimo dos índices relacionados com a intensidade da cor das folhas e das características agronômicas da planta foram estabelecidos e variam com o material de propagação e idade da planta de batata.

Palavras-chave: Solanum tuberosum L., propagação, nível crítico, diagnóstico, clorofilômetro, tabela de cor.

\section{ABSTRACT}

\section{Indexes to assess nitrogen status of potato multiplied by different propagation materials}

Improvement in the efficiency of $\mathrm{N}$ application can be achieved by synchronizing the plant demand with $\mathrm{N}$ supply during the potato cycle. The objective of this study was to determine the optimum values of nitrogen indexes over the cycle of potato grown in a greenhouse, using different propagative materials such as seed tuber, minituber, and sprout tuber, common in the pre-basic seed tuber production. The indexes, determined in the fourth (FL) and the oldest (OL) leaf, were green color intensity, measured by chlorophyll meter and color chart, and agronomic characteristics as leaflet

\footnotetext{
Recebido para publicação em maio de 2010 e aprovado em abril de 2011

${ }^{1}$ Apoio CNPq e FAPEMIG.

${ }^{2}$ Engenheira-Agrônoma, Doutora. Departamento de Fitotecnia, Universidade Federal de Viçosa, Av. P.H. Rolfs, Centro, 36570-000, Viçosa, Minas Gerais, Brasil. Autor para correspondência,mam@vicosa.ufv.br

${ }^{3}$ Engenheiro-Agrônomo, Ph.D. Departamento de Fitotecnia, Universidade Federal de Viçosa, Av. P.H. Rolfs, Centro, 36570-000, Viçosa, Minas Gerais, Brasil. parecefo@ufv.br ${ }^{4}$ Engenheiro-Agrônomo, Doutor. Departamento de Informática, Universidade Federal de Viçosa, Av. P.H. Rolfs, Centro, 36570-000, Viçosa, Minas Gerais, Brasil. cecon@ dpi.ufv.br ${ }^{5}$ Engenheiro-Agronômo, Doutor. Empresa de Pesquisa Agropecuária de Minas Gerais, Vila Gianetti, Casa 46, Campus da UFV, 36570-000, Viçosa, Minas Gerais, Brasil. rfaraujo@ufv.br
}

Rev. Ceres, Viçosa, v. 58, n.3, p. 384-392, mai/jun, 2011 
length, width, area and number. Three experiments were carried out in pots in a greenhouse at the University Federal of Viçosa. In each experiment, arranged in a randomized block design with four replications, there was evaluated six nitrogen rates $\left(0,25,50,100,200\right.$ and $\left.400 \mathrm{mg} \mathrm{dm}^{-3}\right)$. The indexes were determined every 10 days, starting 20 days after plant emergence (DAE). With each propagating material, the SPAD index measured in both the FL and the OL responded differently to the increase in $\mathrm{N}$ and reached the optimal values of 41.3, 40.5, 37.0, 35.8, 36.0, 31.9 and 29.8 g.kg-1 from 20 to $80 \mathrm{DAE}$, respectively when seed tuber was used. In all the propagating material, plant age significantly affected all variables except number of stems or the number of leaves, when it is used sprout tuber or minitubers, respectively. Optimum values of variables over the potato cycle depended upon propagation material and time of evaluation.

Key words: Chlorophyll meter, color chart, critical level, diagnosis, propagation, Solanum tuberosum L.

\section{INTRODUÇÃO}

A batata-semente genética é aquela proveniente de material de reprodução sob a responsabilidade e controle direto de seu obtentor ou introdutor. No atual processo de certificação no Brasil, a partir da semente genética temse a semente básica que pode ser multiplicada por até quatro gerações: G0 (planta in vitro, muda e minitubérculo), G1 (primeira colheita em campo), G2 (segunda colheita em campo) e G3 (terceira colheita em campo). A semente básica origina a classe de batata-semente certificada que é o material propagativo utilizado pelos produtores. A utilização de tubérculo por repetidos ciclos causa o acúmulo de doenças no material propagativo. Isso acarreta a necessidade de produzir tubérculos de elevada sanidade, normalmente, em ambiente protegido, como os das classes básicas G0, G1 e G2 para suprimento do sistema de produção de batata-semente certificada.

Na produção de tubérculos de elevada sanidade é possível utilizar diversos materiais propagativos, dentre os quais tubérculos, minitubérculos colhidos de plântulas oriundas de cultura de tecido e broto de tubérculo-básico, os quais podem apresentar comportamento diferenciado em relação às práticas culturais adotadas. Ranalli et al. (1994) e Kawakami (2007) mostraram diferença de crescimento e produtividade de batata multiplicada no campo por tubérculos e microtubérculos.

Normalmente, em ambiente protegido, o material propagativo é plantado em substrato. Quase sempre, a quantidade de nutriente contido na maioria dos substratos é baixa sendo necessária a adição de fertilizantes. Dentre os nutrientes adicionados ao substrato, o nitrogênio $(\mathrm{N})$ destaca-se. Usualmente é necessário aplicar fertilizante nitrogenado em dose adequada para a obtenção de plantas com número elevado de tubérculos, de tamanho apropriado para a utilização como semente básica. Em condições de solo, a fertilização com nitrogênio aumenta a produção de tubérculos de batata (Bélanger et al., 2000) e otimiza a qua- lidade dos tubérculos (Wu et al., 2007). Dose reduzida de N pode resultar em baixa produtividade e tubérculos pequenos, devido à reduzida área foliar. Por outro lado, dose excessiva de $\mathrm{N}$ favorece o crescimento exagerado das folhas, retarda a maturação do tubérculo, reduz a qualidade e o teor de massa da matéria seca dos tubérculos além de favorecer o desenvolvimento da parte aérea em detrimento dos tubérculos. Portanto, é necessário manejar adequadamente o programa de adubação da cultura.

Melhoria na eficiência de aplicação do $\mathrm{N}$ pode ser conseguida pela sincronização da demanda da planta com o suprimento deste nutriente durante o ciclo da cultura. A dose de $\mathrm{N}$ deve ser sincronizada com o requerimento em tempo real através de aplicações periódicas. Isso pode ser conseguido aplicando-se uma parte do adubo nitrogenado no plantio e o restante de acordo com a necessidade da planta, definida pela avaliação do estado de nitrogênio da planta (ENP). Essas considerações são especificamente válidas para condições de alta lixiviação e em reduzido volume de solo como em vaso. Com essa perspectiva, é necessário caracterizar, periodicamente, o ENP. Usualmente, a avaliação do ENP é acoplada à resposta da planta à adição de $\mathrm{N}$ no solo ou no substrato e pode ser feita por meios diretos e indiretos através de índices apropriadamente calibrados (Fontes \& Araújo, 2006). Mais comumente, o critério para avaliar o ENP é a análise química, em laboratório, dos teores de $\mathrm{N}$ e de $\mathrm{N}-\mathrm{NO}_{3}$ na matéria seca da folha, geralmente na quarta folha completamente desenvolvida a partir do ápice. Tais análises são onerosas, demoradas e realizadas por pessoas qualificadas.

Atualmente, em consonância com a agricultura de precisão, índices ou testes para avaliar o ENP precisam ser rápidos, práticos e eficazes (Fontes, 2001). Assim, estudos têm sido publicados utilizando-se a análise da intensidade do verde da planta. O olho enxerga a cor verde da folha devido, principalmente, às moléculas de clorofila a (verde-azulada) e b (verde-amarelada) que refletem mais o 
verde e absorvem mais azul e vermelho e pouco verde. $\mathrm{O}$ teor de clorofila ou o verde da folha tem sido indicado como índice para avaliar o ENP. Isso devido ao fato de doses diferentes de $\mathrm{N}$ proporcionarem diferentes tons de verde na folha.

Assim, a cor verde da folha, representada pelo teor de clorofila, surgiu como alternativa para avaliar o ENP, pois é possível de ser medida por medidor portátil (Yadava, 1986), ou clorofilômetro, que proporciona leitura instantânea, de maneira não destrutiva das folhas. Várias pesquisas têm demonstrado que o conteúdo de clorofila medido com o clorofilômetro correlaciona-se com a concentração de N na planta e com o rendimento de várias espécies, inclusive batata (Minotti et al., 1994; Gil et al., 2002; Gianquinto, et al. 2003; Busato, 2007), podendo ser usado como ferramenta auxiliar na adubação nitrogenada da cultura no campo.

A intensidade do verde pode ser também avaliada por tabela de cor, como proposto para arroz (Balasubramanian et al., 1999). A tabela de cor é simples, fácil de manusear e de baixo custo, sendo ferramenta alternativa ao clorofilômetro. Estudos têm mostrado haver correlação entre as leituras SPAD e a tabela de cor para o arroz (Shukla et al., 2004). Para avaliar o ENP com base no verde da folha da batata foi proposta a tabela de cor denominada UFV-80Monalisa ${ }^{\circledR}$ (Fontes \& Silva, 2006).

Adicionalmente, características morfológicas da planta, determinadas com facilidade e de forma não destrutiva, como área da folha, número de folhas e altura de plantas, talvez possam ser utilizadas como teste indireto para avaliar o ENP em alternativa ou em complementaridade à análise do verde da folha (Fontes, 2001). São escassos os trabalhos buscando utilizar características morfológicas da planta como critério de avaliação do ENP.

Qualquer que seja o teste, é necessário interpretar os valores obtidos. Para isso, é necessário haver a disponibilidade do valor considerado referencial ou ótimo para cada teste em determinados estádios fisiológicos da planta e sistemas de produção utilizado. Os testes mencionados para avaliar o ENP podem tornar-se uma alternativa viável para o sistema de produção de batata-semente em substrato, em condição de estufa. Não foram encontrados trabalhos com tal direcionamento na cultura da batata, exceto pela citação de Gerendás \& Pieper (2001). Ademais, não foram encontrados na literatura trabalhos que procuram avaliar a evolução dos índices para avaliar o ENP ao longo do tempo no sistema de produção de batata-semente básica em substrato.

Assim, o objetivo foi determinar os valores de índices indiretos e não destrutivos de avaliação do ENP, em diferentes fases do desenvolvimento da planta de batata cultivada em ambiente protegido, utilizando distintos materiais propagativos.

\section{MATERIAL E MÉTODOS}

Três experimentos foram conduzidos em ambiente protegido do Departamento de Fitotecnia da Universidade Federal de Viçosa. A estrutura de proteção seguiu o modelo capela, com largura de $9 \mathrm{~m}$, comprimento de $40 \mathrm{~m}$, altura dos esteios laterais de $3 \mathrm{~m}$, altura do vão central de $3,8 \mathrm{~m}$, com as partes superiores, frontais e laterais fechadas com filme de polietileno transparente de $0,1 \mathrm{~mm}$ de espessura.

Em cada experimento foi utilizado diferente material de propagação. No primeiro foi utilizado tubérculo-semente básica G0, classificada no tipo II (40-50 mm de diâmetro transversal; IMA, 2003) com massa média de $40 \mathrm{~g}$. Esse material foi denominado de tubérculo-semente. No experimento 2, foi usado tubérculo-semente básica G0, classificada no tipo V (16-23 mm de diâmetro transversal; IMA, 2003) com a massa média de $5 \mathrm{~g}$. Esse material foi denominado de minitubérculo. No terceiro, foi usada gema destacada de tubérculo-semente básica G0, com 0,5 cm de comprimento. Esse material foi denominado de "broto". Cada broto foi destacado do tubérculo-mãe, imerso em solução a $2 \%$ de hipoclorito de sódio por dois minutos, lavados por três vezes com água e secos em papel toalha.

Em cada experimento foram avaliadas seis doses de $\mathrm{N}$ $\left(0 ; 25 ; 50 ; 100 ; 200 \mathrm{e} 400 \mathrm{mg} \mathrm{dm}^{-3}\right)$ adicionadas ao substrato comercial contido em vaso de $3 \mathrm{dm}^{3}$. Os tratamentos foram arranjados no delineamento experimental de blocos ao acaso, com quatro repetições. A fonte de $\mathrm{N}$ foi o nitrato de amônio, sendo $10 \%$ de cada dose aplicada em préplantio e o restante via água de irrigação, diariamente, por 30 dias. Em todos os experimentos, o substrato foi uniformemente adubado com macro, com o $\mathrm{N}$ aplicado de acordo com os tratamentos avaliados e micronutrientes e irrigado quando necessário. Os experimentos com a utilização do tubérculo-semente e broto foram iniciados em 20/ 6/2007 e com minitubérculo em 20/8/2007.

Aos 20 dias após o plantio (DAP) iniciaram-se as avaliações que, posteriormente, ocorreram a cada 10 dias até a colheita final. Assim, foram realizadas sete avaliações, aos 20, 30, 40, 50, 60, 70 e 80 dias após o plantio para os experimentos com tubérculo-semente e broto, e cinco avaliações, aos 20, 30, 40, 50 e 60 após o plantio para o experimento com minitubérculo. A colheita final foi realizada quando a parte aérea das plantas estava seca, que ocorreu aos 90, 90 e 74 dias após o plantio, respectivamente. Os tubérculos foram colhidos e contados (dados não mostrados).

As variáveis foram avaliadas na quarta folha expandida a partir do ápice (QF) e na folha mais velha (FV). Os índices relacionados com a intensidade da cor verde das folhas foram medidos no folíolo terminal, entre 8:00 e 11:00 horas, com dois equipamentos, clorofilômetro portátil (SPAD-502 da Soil Plant Analysis Development) e tabela 
de cor desenvolvida para arroz (Balasubramanian et al., 1999) que apresenta a variação de 1 a 6 , correspondentes às cores verde-amarelada a verde intenso, respectivamente. Adicionalmente, com as medições efetuadas com o SPAD foram calculadas quatro variáveis relativas ou normalizadas: a) gradiente da leitura SPAD na QF (GSQF) que foi calculado pela divisão do resultado da diferença entre o valor SPAD na QF da planta em um tratamento e o valor SPAD na QF da planta no tratamento zero de N pela dose de N nesse tratamento; b) gradiente da leitura SPAD na QF (GSnQF) que foi calculado pela divisão do valor SPAD na QF da planta em um tratamento dividido pela dose de $\mathrm{N}$ nesse tratamento; c) valor relativo do índice SPAD na QF (VRSQF), calculado pela a razão entre o valor da leitura SPAD na QF em determinado tratamento dividido pelo valor SPAD com a dose zero de $\mathrm{N}$; d) relação (SFV/SQF), calculado pela relação entre os valores de SPAD na FV e QF. Os índices relacionados com características agronômicas da planta foram comprimento, largura, área e número de folíolos da quarta folha $(\mathrm{QF})$ e da folha mais velha (FV); número de folhas vivas; comprimento e número de hastes.

Para determinar a resposta de cada variável às doses de $\mathrm{N}$ e às épocas de amostragem, em cada material de propagação, foram realizadas análises de variância e de regressão, utilizando-se o programa SAEG (1993). A interação entre dose de $\mathrm{N}$ e época de amostragem foi desdobrada independentemente da significância. Para cada época de amostragem foi ajustado um modelo que melhor descrevesse a relação entre os valores da variável avaliada e de doses de nitrogênio. Nesse modelo foi introduzido o valor da dose ótima de $\mathrm{N}$ obtendo-se o valor ótimo de cada variável em cada época de amostragem (Fontes, 2001). Foi considerada dose ótima de $\mathrm{N}$ aquela que propiciou o número máximo de tubérculos na colheita final e que foi 254, 231 e $183 \mathrm{mg} \mathrm{dm}^{-3}$ para os materiais de propagação tubérculo-semente, minitubérculo e broto, respectivamente (resultados não mostrados).

\section{RESULTADOS E DISCUSSÃO}

\section{Valores relacionados com a cor verde}

Todas as variáveis relacionadas com a cor das folhas (Tabela 1), exceto SFV/SQF, foram influenciadas por doses de $\mathrm{N}$ ao ser usado o tubérculo-semente como material de propagação. Por outro lado, ao ser utilizado o broto, todas as variáveis relacionadas com a cor das folhas não foram influenciadas por doses de $\mathrm{N}$, exceto o índice SPAD aos 40 e 60 dias após o plantio.

Em cada material de propagação, o índice SPAD medido na quarta folha $(\mathrm{QF})$ e na folha velha $(\mathrm{FV})$ respondeu de forma diferenciada ao incremento na dose de N. Os modelos das relações entre doses de $\mathrm{N}$ e índice SPAD na
QF, determinados nas diversas épocas durante o ciclo da cultura, em cada material de propagação, estão na Tabela 2. Os modelos para a folha velha (FV) seguiram a mesma tendência. Na Figura 1 é mostrada a representação gráfica da relação entre doses de $\mathrm{N}$ e leitura SPAD na QF para cada material de propagação, na avaliação realizada aos 60 dias após o plantio (DAP). Aumento do índice SPAD e do teor de clorofila na folha da batata com o incremento
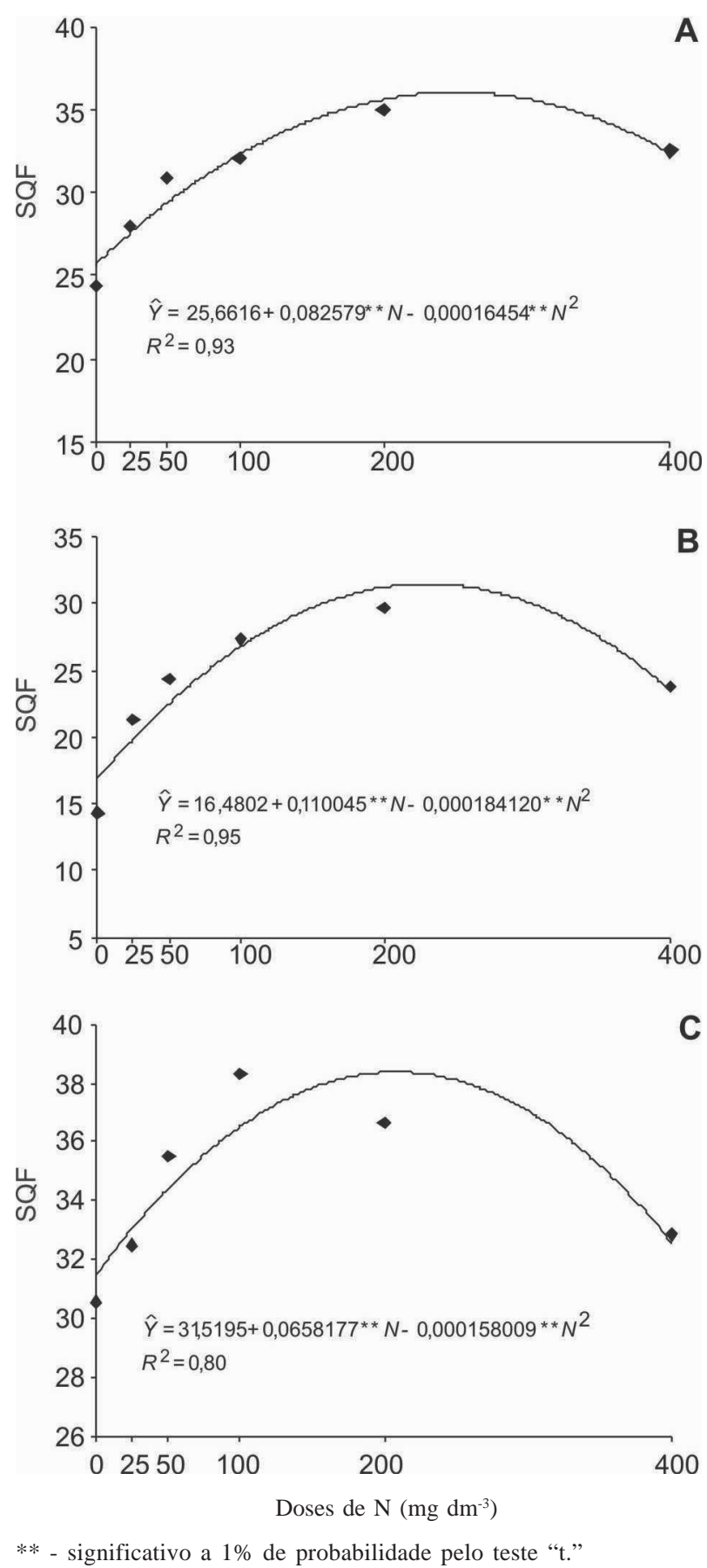

Figura 1. Relação entre os valores dos índices SPAD na quarta folha da batata (SQF) e doses de nitrogênio (N), aos 60 dias após o plantio com os materiais de propagação tubérculo-semente (A), minitubérculo (B) e broto (C).

Rev. Ceres, Viçosa, v. 58, n.3, p. 384-392, mai/jun, 2011 
de doses de $\mathrm{N}$ tem sido obtido por diversos autores (Minotti et al., 1994; Gil et al., 2002; Busato, 2007).

Todas as variáveis relacionadas com a cor das folhas (Tabela 1) foram influenciadas por épocas de avaliação, com todos os materiais de propagação. $\mathrm{O}$ valor ótimo do índice SPAD medido na quarta folha (SQF) e na folha velha (SFV) tendeu a decrescer ao longo do ciclo da cultura em cada material de propagação (Tabela 2). Decréscimo do índice SPAD em folha de batata ao longo do ciclo da cultura foi verificado por outros autores (Minotti et al., 1994; Sampaio Júnior et al., 2008). Rastami et al. (2008) obtiveram ascensão e queda no valor do índice SPAD ao longo do ciclo da cultura do milho e chamaram de "maturidade fotossintética" o ponto de máximo teor de clorofila o qual, não necessariamente, corresponde ao máximo de tamanho da folha. O modelo de equação relacionando valor do índice SPAD e ciclo da cultura depende da disponibilidade de $\mathrm{N}$ no estádio inicial da cultura, fortemente determinado pela dose de $\mathrm{N}$ aplicada no plantio.
Independentemente do material de propagação, o índice SPAD na QF alcançou valor ótimo abaixo de 43,02, que foi o valor ótimo determinado por Busato (2007), aos 21 dias após a emergência do cultivar Ágata, no campo. Também no campo, Gil et al. (2002) encontraram o valor de 44,9, aos 20 dias após a emergência para o cultivar Monalisa. Com tubérculo-semente como material de propagação, em condição de campo, Minotti et al. (1994) citaram valores de 49 a 56 para o índice SPAD na QF, determinados entre 29 e 37 dias após o plantio e dependendo do ano e localidade. Em estufa, aos 37 dias após o plantio do cultivar Monalisa, nos meses de março a junho, associado à máxima produção de tubérculos, o valor crítico do índice SPAD na QF foi 45,71 e 47,94 ao ser utilizado como material de propagação minitubérculo e broto, respectivamente (Sampaio Júnior et al., 2008).

Houve efeito de doses de $\mathrm{N}$ e de épocas de avaliação sobre a intensidade da cor verde da QF e FV determinada pela tabela de cor (TC) em todos os materiais de propaga-

Tabela 1. Valores ótimos ${ }^{1}$ das características relacionadas com a cor das folhas avaliadas durante o ciclo da batata multiplicada por tubérculo-semente, broto e minitubérculo

\begin{tabular}{|c|c|c|c|c|c|c|c|}
\hline \multirow{2}{*}{ Características } & \multicolumn{7}{|c|}{ Ciclo da cultura (Dias após o plantio) } \\
\hline & 20 & 30 & 40 & 50 & 60 & 70 & 80 \\
\hline \multicolumn{8}{|c|}{ Tubérculo-semente } \\
\hline SQF - (SPAD Quarta Folha) & 41,3 & 40,5 & 37,0 & 35,8 & 36,0 & 31,9 & 29,8 \\
\hline SFV - (SPAD Folha Velha) & 41,5 & 43,2 & 37,5 & 34,3 & 35,4 & 23,2 & 22,3 \\
\hline TCQF - (Tabela de cor) & 5,2 & 3,3 & 4,4 & 4,4 & 4,1 & 2,2 & 1,1 \\
\hline TCFV - (Tabela de cor) & 6,0 & 3,3 & 4,4 & 4,4 & 3,7 & 2,1 & 1,0 \\
\hline GSQF x 100 (Gradiente SPAD) & 0,4 & 1,8 & 3,3 & 1,1 & 5,4 & 5,1 & 6,0 \\
\hline GSnQF x 100 (Gradiente SPAD) & 9,0 & 7,8 & 7,9 & 6,8 & 4,7 & 4,1 & 4,7 \\
\hline VRSQF (Valor relativo de SPAD) & 1,00 & 1,12 & 1,18 & 1,16 & 1,49 & 1,39 & 1,70 \\
\hline SFV/SQF (Relação entre SPAD) & 1,01 & 1,05 & 1,06 & 1,01 & 0,96 & 0,83 & 0,92 \\
\hline \multicolumn{8}{|c|}{ Broto } \\
\hline SQF - (SPAD Quarta Folha) & 43,8 & 38,9 & 36,8 & 36,2 & 38,2 & 32,7 & 28,2 \\
\hline SFV - (SPAD Folha Velha) & 44,7 & 40,8 & 38,8 & 37,7 & 37,0 & 28,9 & 28,0 \\
\hline TCQF - (Tabela de cor) & 5,3 & 3,9 & 3,6 & 3,6 & 3,9 & 3,0 & 2,3 \\
\hline TCFV - (Tabela de cor) & 5,3 & 3,9 & 3,6 & 3,6 & 3,9 & 3,0 & 2,3 \\
\hline GSQF x 100 (Gradiente SPAD) & 2,6 & 1,3 & 0,3 & 1,2 & 5,1 & 1,6 & 2,3 \\
\hline GSnQF x 100 (Gradiente SPAD) & 9,3 & 7,9 & 4,9 & 7,3 & 10,6 & 4,7 & 6,2 \\
\hline VRSQF (Valor relativo de SPAD) & 1,04 & 0,98 & 1,00 & 0,99 & 1,25 & 1,03 & 1,02 \\
\hline SFV/SQF (Relação entre SPAD) & 0,76 & 1,05 & 1,07 & 1,05 & 0,95 & 0,89 & 1,07 \\
\hline \multicolumn{8}{|c|}{ Minitubérculo } \\
\hline SQF - (SPAD Quarta Folha) & 33,9 & 36,1 & 37,9 & 35,8 & 32,0 & ND & ND \\
\hline SFV - (SPAD Folha Velha) & $\mathrm{ND}^{2}$ & 33,3 & 33,4 & 34,3 & 26,2 & ND & ND \\
\hline TCQF - (Tabela de cor) & 5,0 & 5,0 & 4,9 & 4,1 & 2,1 & ND & ND \\
\hline GSQF x 100 (Gradiente SPAD) & 4,1 & 1,4 & 3,6 & 3,4 & 9,3 & ND & ND \\
\hline GSnQF x 100 (Gradiente SPAD) & 7,7 & 6,4 & 9,1 & 4,2 & 2,4 & ND & ND \\
\hline VRSQF (Valor relativo de SPAD) & 1,06 & 1,06 & 1,05 & 1,12 & 2,30 & ND & ND \\
\hline SFV/SQF (Relação entre SPAD) & ND & 0,92 & 0,88 & 0,98 & 0,85 & ND & ND \\
\hline
\end{tabular}

${ }^{1}$ Quando houve efeito de dose, o valor foi estimado com a dose ótima de N; quando não houve efeito de dose de N, utilizou-se a média da variável.

${ }^{2} \mathrm{ND}=$ Não determinado, pois não havia FV ou a planta já havia senescido. 
ção, exceto para broto onde não houve efeito de dose de N. Os valores de TCQF e TCFV tenderam a decrescer ao longo do ciclo da cultura independente do material de propagação (Tabela 1). O valor obtido na QF com a tabela de cor foi semelhante ao valor crítico encontrado por Busato (2007), 4,34 aos 21 DAE, cultivar Ágata, no campo. A tabela de cor é método simples, fácil de manusear e de baixo custo (Witt et al., 2005). Fontes \& Silva (2006) desenvolveram uma tabela de cor para o cultivar Monalisa cultivado no campo. $\mathrm{O}$ manejo do $\mathrm{N}$ baseado no uso de tabela de cor pode evitar a supérflua aplicação de $\mathrm{N}$ em arroz (Singh et al., 2002), podendo ser usada por rizicultores (Alam et al., 2005), sendo a cor crítica na tabela de cor igual a 5,0 (Nachimuthu et al., 2007).

Observações da intensidade da cor da QF e FV ao longo do ciclo da batata, apesar de ser método visual e subjetivo, podem contribuir para avaliação do estado de $\mathrm{N}$ da planta, desde que adequadamente calibrada. Recomendação da adubação nitrogenada baseada em observações visuais da "aparência" da planta, considerando principalmente cor e número de folhas, diâmetro do caule e altura do tomateiro foi proposta por Fontes \& Araújo (2006).

Os valores relativos dos índices relacionados com a cor verde da QF e FV foram: GS e GSn ou gradiente SPAD; VRS ou valor relativo do SPAD e relação entre SPAD nas folhas. Os valores ótimos destes índices relativos, ao longo do ciclo da cultura, estão na Tabela 1. É sabido que outros fatores que não somente $\mathrm{N}$ podem afetar o teor de clorofila das folhas e afetar os valores dos índices relacionados com o verde da folha. Tentando minimizar essa influência, Schepers et al. (1992) e Piekielek et al. (1995) propuseram usar valor relativo ou normalizado do índice SPAD, utilizando-se a leitura em planta de "área adequadamente fertilizada" ou bem adubada com $\mathrm{N}$ que poderia ser usada para padronizar o teste entre híbridos, localidades e estádio de crescimento. A variabilidade entre doses de nitrogênio e o estresse nitrogenado em milho foi reduzido com o uso de valores normalizados comparados com valores absolutos da leitura do clorofilômetro (Hawkins et al., 2007). Arregui et al. (2006) mostraram que a utilização de índice normalizado ou relativizado da leitura do clorofilômetro diminuiu a porcentagem de erro na predição da produtividade de trigo em relação a valores absolutos de leitura, além de poder ser utilizado com diferentes cultivares e ambientes.

Os índices GS e GSn medem o incremento observado na leitura SPAD devido à adição de $\mathrm{N}$, considerando ou não a contribuição do $\mathrm{N}$ existente no substrato, respectivamente. Ambos têm utilidade na avaliação da eficiência do $\mathrm{N}$ adicionado como fertilizante sobre o valor da leitura

Tabela 2. Equações ajustadas para o índice SPAD na quarta folha da batata aos 20 (SQF20), 30 (SQF30), 40 (SQF40), 50 (SQF50), 60 (SQF60), 70 (SQF70) e 80 (SQF80) dias após o plantio em função de doses de nitrogênio ( $\mathrm{N}^{\mathrm{mg} \mathrm{dm}} \mathrm{dm}^{-3}$ ), com os três materiais de propagação

\begin{tabular}{|c|c|c|}
\hline Características & Equações ajustadas & $\mathbf{R}^{2} / \mathbf{r}^{2}$ \\
\hline \multicolumn{3}{|c|}{ Tubérculo-semente } \\
\hline SQF20 & $\hat{\mathrm{Y}}=41,3$ & - \\
\hline SQF30 & $\hat{\mathrm{Y}}=35,1027+0,038093 * \mathrm{~N}-0,0000668077 * * * \mathrm{~N}^{2}$ & 0,92 \\
\hline SQF40 & $\hat{\mathrm{Y}}=31,2313+0,0379933 * \mathrm{~N}-0,0000596237 * * * \mathrm{~N}^{2}$ & 0,98 \\
\hline SQF50 & $\hat{\mathrm{Y}}=32,1264+0,0145696 * * \mathrm{~N}$ & 0,86 \\
\hline SQF60 & Na Figura 1 & \\
\hline SQF70 & $\hat{\mathrm{Y}}=23,2964+0,0657991 * * \mathrm{~N}-0,000125034 * \mathrm{~N}^{2}$ & 0,79 \\
\hline SQF80 & $\hat{\mathrm{Y}}=19,3459+0,0803383 * * \mathrm{~N}-0,00015384 * * \mathrm{~N}^{2}$ & 0,79 \\
\hline \multicolumn{3}{|c|}{ Broto } \\
\hline SQF20 & $\hat{Y}=43,8$ & - \\
\hline SQF30 & $\hat{\mathrm{Y}}=38,9$ & - \\
\hline SQF40 & $\hat{\mathrm{Y}}=34,9304+0,0101198 * * \mathrm{~N}$ & 0,73 \\
\hline SQF50 & $\hat{\mathrm{Y}}=36,2$ & - \\
\hline SQF60 & Na Figura 1 & \\
\hline SQF70 & $\hat{\mathrm{Y}}=32,7$ & - \\
\hline SQF80 & $\hat{Y}=28,2$ & - \\
\hline \multicolumn{3}{|c|}{ Minitubérculo } \\
\hline SQF20 & $\hat{\mathrm{Y}}=33,9$ & - \\
\hline SQF30 & $\mathrm{v}=34,4336+0,00709493 * \mathrm{~N}$ & 0,96 \\
\hline SQF40 & $\hat{\mathrm{Y}}=37,9$ & - \\
\hline SQF50 & $\hat{\mathrm{Y}}=31,6538+0,0290099 * \mathrm{~N}-0,0000481182 * * * \mathrm{~N}^{2}$ & 0,88 \\
\hline SQF60 & Na Figura 1 & \\
\hline
\end{tabular}


SPAD, considerando ou não a quantidade de $\mathrm{N}$ fornecida pelo substrato. Os valores de GS e GSn são expressos em valor da leitura SPAD por mg de $\mathrm{N}$ por $\mathrm{dm}^{3}$ de substrato, considerando e não considerando o teor de $\mathrm{N}$ no substrato, respectivamente.

A relação SFV/SQF é a relação entre intensidade da cor verde da folha velha (FV) e da folha completamente expandida $(\mathrm{QF})$. A relação ótima $>1$ indica que a planta acumula mais $\mathrm{N}$ na folha velha. Com a relação ótima $<1$ há indicação da possível ocorrência de senescência e translocação de $\mathrm{N}$ para a folha jovem e que a planta não estaria necessitando receber aplicação de N.

A utilização de índices relativos na avaliação do estado de $\mathrm{N}$ e na recomendação da dose de $\mathrm{N}$ tem sido utilizada em algumas culturas, incluindo a batata (Olivier et al., 2006). Esses autores mencionaram que devido ao efeito de especificidade de local, o uso de valores medidos diretamente pelo clorofilômetro durante a estação de crescimento da batata foi menos eficaz em estabelecer a necessidade de suprir $\mathrm{N}$ do que um valor relativo da leitura com o clorofilômetro. Entretanto, a possibilidade do uso de valo- res relativos precisa ser mais bem avaliada principalmente no estabelecimento da parcela "bem adubada com N".

A cor e os espectros de absorção e reflexão da luz dependem dos pigmentos existentes na folha, caroteno, xantofila e clorofilas a e b, que absorvem e refletem determinados comprimentos de onda da luz incidente. A cor verde reflete pouca energia radiante. Deficiências de nutrientes com reflexo na concentração de clorofila e de carotenóides têm influência sobre a absorção e reflexão da luz na folha (Baltzer \& Thomas, 2005). Assim, os índices relacionados com a intensidade da cor verde das folhas da batata podem ser afetados por fatores que não a disponibilidade de N, como por exemplo, ano, localidade (Minotti et al., 1994) e material de propagação (Sampaio Júnior et al., 2008). Em outras espécies tem sido reportada a influência de fatores como época do ano, cultivar, data de determinação, estádio de desenvolvimento da planta e temperatura sobre a intensidade da coloração verde da folha e leitura pelo clorofilômetro.

Especificamente no presente experimento, provavelmente, a utilização de ambiente protegido com polietileno é um

Tabela 3. Valores ótimos ${ }^{1}$ das características agronômicas das plantas avaliadas durante o ciclo da batata multiplicada por tubérculosemente, broto e minitubérculo

\begin{tabular}{|c|c|c|c|c|c|c|c|}
\hline \multirow{2}{*}{ Características } & \multicolumn{7}{|c|}{ Ciclo da cultura (Dias após o plantio) } \\
\hline & 20 & 30 & 40 & 50 & 60 & 70 & 80 \\
\hline \multicolumn{8}{|c|}{ Tubérculo-semente } \\
\hline CQF - (Comprimento - cm) & 4,7 & 17,3 & 18,5 & 19,5 & 18,7 & 18,5 & 18,5 \\
\hline LQF - (Largura - cm) & 6,7 & 10,3 & 10,5 & 11,0 & 10,4 & 9,9 & 9,8 \\
\hline AFQF - Área quarta folha $\left(\mathrm{cm}^{2}\right)$ & 91 & 121 & 127 & 132 & 126 & 123 & 122 \\
\hline AFFV - Área da folha velha $\left(\mathrm{cm}^{2}\right)$ & 81 & 95 & 90 & 96 & 88 & 92 & 92 \\
\hline NFQF - ( $\mathrm{N}^{\circ}$ de folíolos $)$ & 3,9 & 5,7 & 5,8 & 6,6 & 6,4 & 5,7 & 6,1 \\
\hline $\mathrm{NF}$ - ( $\mathrm{N}^{\circ}$ de folhas vivas $)$ & 4,3 & 7,7 & 8,9 & 8,5 & 10,5 & 8,2 & 7,0 \\
\hline $\mathrm{CH}-($ Comprimento da haste $-\mathrm{cm})$ & 8,5 & 16,7 & 21,3 & 21,8 & 21,0 & 22,2 & 22,3 \\
\hline \multicolumn{8}{|c|}{ Broto } \\
\hline CQF - (Comprimento - cm) & 7,4 & 13,9 & 16,2 & 16,6 & 17,1 & 17,1 & 17,4 \\
\hline LQF - (Largura - cm) & 4,7 & 7,4 & 9,0 & 10,4 & 10,0 & 9,8 & 9,3 \\
\hline AFQF - Área quarta folha $\left(\mathrm{cm}^{2}\right)$ & 81 & 101 & 113 & 121 & 124 & 119 & 117 \\
\hline AFFV - Área da folha velha $\left(\mathrm{cm}^{2}\right)$ & 78 & 88 & 89 & 91 & 88 & 83 & 92 \\
\hline $\mathrm{NFQF}$ - ( $\mathrm{N}^{\circ}$ de folíolos $)$ & 3,6 & 4,3 & 5,1 & 5,0 & 4,8 & 4,9 & 4,8 \\
\hline NF- ( $\mathrm{N}^{\circ}$ de folhas vivas) & 3,5 & 5,7 & 8,3 & 9,1 & 9,8 & 8,9 & 8,2 \\
\hline $\mathrm{CH}$ - (Comprimento da haste $-\mathrm{cm})$ & 4,6 & 9,5 & 13,9 & 16,3 & 18,9 & 18,3 & 16,7 \\
\hline \multicolumn{8}{|c|}{ Minitubérculo } \\
\hline CQF - (Comprimento - cm) & 5,8 & 25,4 & 27,6 & 27,2 & 27,2 & ND & ND \\
\hline LQF - (Largura - cm) & 4,1 & 12,9 & 16,1 & 16,7 & 16,9 & ND & ND \\
\hline AFQF - Área quarta folha $\left(\mathrm{cm}^{2}\right)$ & 78 & 173 & 185 & 192 & 200 & ND & ND \\
\hline AFFV - Área da folha velha $\left(\mathrm{cm}^{2}\right)$ & ND & 105 & 109 & 109 & 122 & ND & ND \\
\hline NFQF - ( $\mathrm{N}^{\circ}$ de folíolos $)$ & 2,0 & 8,3 & 8,8 & 8,5 & 11,0 & ND & ND \\
\hline $\mathrm{NF}$ - ( $\mathrm{N}^{\circ}$ de folhas vivas $)$ & 2,8 & 10,3 & 11,3 & 12,3 & 16,6 & ND & ND \\
\hline $\mathrm{CH}$ - (Comprimento da haste $-\mathrm{cm})$ & 5,9 & 18,3 & 34,3 & 38,6 & 39,1 & ND & ND \\
\hline
\end{tabular}

${ }^{1}$ Quando houve efeito de dose, o valor foi estimado com a dose ótima de N; quando não houve efeito de dose de N, utilizou-se a média da variável.

ND = Não determinado, pois não havia FV ou a planta já havia senescido.

Rev. Ceres, Viçosa, v. 58, n.3, p. 384-392, mai/jun, 2011 
fator que pode influenciar a intensidade do verde das folhas. O polietileno de baixa densidade, material mais empregado para a cobertura de estufas, tem transparência à irradiação solar na faixa de $80 \%$, significando menos luz e energia no interior da estufa do que em condições de campo. Balasubramanian et al. (1999) comentaram que em cultivo do arroz durante dias continuamente nublado, quando a radiação é baixa, o nível adequado da leitura SPAD nas folhas é $90 \%$ daquele em cultura plantada em período de intensa energia. Portanto, como os índices relacionados com a intensidade da cor verde das folhas podem ser influenciados por fatores bióticos e abióticos é necessário calibrar os valores dos mesmos em cada condição específica.

\section{Valores relacionados com características agronômicas}

As características comprimento $(\mathrm{C})$, largura (L), área e número de folíolos na $\mathrm{QF}$ e na $\mathrm{FV}$, além do número de folhas vivas (NF), número de hastes $(\mathrm{NH})$ e comprimento da haste $(\mathrm{CH})$ responderam de forma diferenciada ao incremento de doses de $\mathrm{N}$ e época de avaliação, dependendo do material de propagação. Dose de $\mathrm{N}$ influenciou significativamente todas as variáveis relacionadas às características agronômicas quando foi utilizado minitubérculo; não influenciou o número de hastes por planta quando foi utilizado broto e também não influenciou o número de folíolos e comprimento de haste quando foi utilizado tubérculo-semente. Época de amostragem influenciou significativamente todas as variáveis relacionadas às características agronômicas quando foi utilizado tubérculo-semente; não influenciou o número de hastes por planta quando foi utilizado broto e também não influenciou o número de folíolos quando foi utilizado minitubérculo. $\mathrm{O}$ número ótimo de hastes por planta, na média geral dos tratamentos foi 3,8; 1,0 e 1,4 com os materiais de propagação tubérculo-semente, broto e minitubérculo, respectivamente. O valor ótimo de cada variável ao longo do ciclo da cultura considerando cada material propagativo está mostrado na Tabela 3.

$\mathrm{O}$ efeito de doses de $\mathrm{N}$ sobre as características agronômicas da QF e da FV da batata foi, aparentemente, menos pronunciado do que o obtido no campo por Busato (2007). Tanto no campo quanto em ambiente protegido, as características das folhas são importantes na fotossíntese. Segundo Vos \& Van Der Putten (1998), o efeito dominante do fornecimento de $\mathrm{N}$ à batata, em ambiente protegido, foi sobre o tamanho da folha que apresenta baixa taxa de fotossíntese em condição de estufa de vidro. Essa "estratégia da batata" para adaptação à condição de limitação pode ser reconhecida em outras espécies pelo pequeno efeito do suprimento de $\mathrm{N}$ na eficiência de uso da radiação, sendo que o inverso ocorre com espécies que apresentam a "estratégia do milho" (Vos et al., 2005).

\section{CONCLUSÕES}

Com cada material de propagação, o índice SPAD medido tanto na QF quanto na FV respondeu de forma diferenciada ao incremento na dose de $\mathrm{N}$ e atingiu os valores ótimos de 41,3; 40,5; 37,0; 35,8; 36,0; 31,9 e 29,8 dos 20 aos 80 DAE, respectivamente ao ser utilizado o tubérculo-semente básica.

Com todos os materiais de propagação, a idade da planta influencia significativamente todas as variáveis, exceto o número de hastes ou o número de folhas quando é utilizado broto ou minitubérculo, respectivamente.

O valor ótimo dos índices relacionados com a intensidade da cor das folhas e das características agronômicas da planta foram estabelecidos e variam com o material de propagação e idade da planta de batata.

\section{REFERÊNCIAS}

Alam MM, Ladha JK, Khan SR, Rashid HU, Khan AH \& Buresh RJ (2005) Leaf color chart for managing nitrogen fertilizer in lowland rice in Bangladesh. Agronomy Journal, 97:949-959.

Arregui LM, Lasa B, Lafarga A, Iraneta I, Baroja E \& Quemada M (2006) Evaluation of chlorophyll meters as tools for $\mathrm{N}$ fertilization in winter wheat under humid Mediterranean conditions. European Journal of Agronomy, 24:140-148.

Balasubramanian V, Morales AC, Cruz RT \& Abdulrachman S (1999) On-farm adaptation of knowledge-intensive nitrogen management technologies for rice system. Nutrient Cycling in Agroecosystems, 53:59-69.

Baltzer JL \& Thomas SC (2005) Leaf optical responses to light and soil nutrient availability in temperate deciduous trees. American Journal of Botany, 92:214-223.

Bélanger GW, Walsh JR, Richards JE, Milburn PH \& Ziadi N (2000) Critical nitrogen curve and nitrogen nutrition index for potato in Eastern Canada. American Journal of Potato Research, 78:355-364.

Busato C (2007) Características da planta, teores de nitrogênio nas folhas e produtividade de tubérculos de cultivares de batata em função de doses de nitrogênio. Dissertação de Mestrado. Universidade Federal de Viçosa, Viçosa, 142p.

Fontes PCR (2001) Diagnóstico do estado nutricional das plantas. Viçosa, UFV. 122p.

Fontes PCR \& Araújo C (2006) Use of chlorophyll meter and plant visual aspect for nitrogen management in tomato fertirrigation. Journal of Applied Horticulture, 8:8-11.

Fontes PCR \& Silva MCC (2006) Proposição de uma tabela de cor (UFV 80 - Monalisa) para a avaliação do estado de nitrogênio da batateira. Batata Show, 6:16.

Gerendás J \& Pieper I (2001) Suitability of the SPAD meter and the petiole nitrate test for nitrogen management in nursery potatoes. In: Horst WJ, Schenk MK, Burkert A, Claassen N, Flessa H, Frommer WB, Goldbach H, Olfs HW, Romheld V, Sattelmacher B, Schmidhalter U, Schubert S, Wirén NV \& Witternmayer L (Eds.). Plant nutrition - Food security of agro-ecosystems. Dordrecht, Kluwer Academic Publishers. p.716-717.

Gianquinto G, Sambo P \& Bona S (2003) The use of SPAD-502 chlorophyll meter for dynamically optimizing the nitrogen supply in potato crop: A methodological approach. Acta Horticulturae, 607:197-204. 
Gil PT, Fontes PCR, Cecon PR \& Ferreira FA (2002) Índices SPAD para diagnóstico do estado de nitrogênio e para o prognóstico da produtividade da batata. Horticultura Brasileira, 20:611-615.

Hawkins JA, Sawyer JE \& Barker DW (2007) Using elative chlorophyll meter values to determine nitrogen application rates for corn. Agronomy Journal, 99:1034-1040.

IMA (2003) Instituto mineiro de agropecuária. Portaria n.567, 30 de Janeiro de 2003.

Kawakami J (2007) Efeito da classe de maturação de cultivares no crescimento e produtividade de plantas de batata originadas de microtubérculos. Horticultura Brasileira, 25:54.

Minotti PL, Halseth DE \& Sieczka JB (1994) Field chlorophyll measurements to asses the nitrogen status of potato varieties. HortScience, 29:1497-1500.

Nachimuthu G, Velu V, Malarvizhi P, Ramasamy S \& Gurusamy L (2007) Standardization of leaf colour chart based nitrogen management in direct wet rice (Oryza sativa L.). Journal of Agronomy, 6:338-343.

Olivier M, Goffart JP \& Ledent JF (2006) Threshold value for chlorophyll meter as decision tool for nitrogen management of potato. Agronomy Journal, 98:496-506.

Piekielek WP, Fox RH, Toth JD \& Macneal KE (1995) Use of a chlorophyll meter at the early dent stage of corn to evaluate nitrogen sufficiency. Agronomy Journal, 87:403-408.

Ranalli P, Bassi F, Ruaro G, Re P, Candilo M \& Mandolino G (1994) Microtuber and minituber production and field performance compared with normal tubers. Potato Research, $37: 383-39$.

Rastami M, Koocheki AR, Mahallati MN \& Kafi M (2008) Evaluation of chlorophyll meter (SPAD) data for prediction of nitrogen status in corn (Zea mays L.). American-Eurasian Journal Agriculture Science, 3:79-85.

SAEG (1993) Sistema para análises estatísticas. v. 5.0. Viçosa, Fundação Artur Bernardes.
Sampaio Júnior JD, Fontes PCR, Moreira MA \& Guimarães MA (2008) Produção de mini-tubérculo semente de batata, em função de doses de nitrogênio aplicadas ao substrato. Bioscience Journal, 24:1-9.

Schepers JS, Francis DD, Vigil M \& Below FE (1992) Comparison of corn leaf nitrogen concentration and chlorophyll meter readings. Communications in Soil Science and Plant Analysis, 23:2173-2187.

Shukla AK, Ladha JK, Singh VK, Dwivedi BS, Balasubramanian V, Gupta RK, Sharna SK, Singh Y, Pathak H, Pandey PS, Padre AT \& Yadava RL (2004) Calibrating the leaf color chart for nitrogen management in different genotypes or rice and wheat in a systems perspective. Agronomy Journal, 96:1606-1621.

Singh B, Singh Y, Ladha JK, Bronson KF, Balasubramanian V, Singh J \& Khind CS (2002) Chlorophyll meter and leaf color chart based nitrogen management for rice and wheat in Northwestern India. Agronomy Journal, 94:821-829.

Vos J \& Van Der Putten PEL (1998) Effect of nitrogen supply on leaf growth, leaf nitrogen economy and photosynthetic capacity in potato. Field Crop Research, 59:63-72.

Vos J, Van Der Putten PEL \& Birch CJ (2005) Effect of nitrogen supply on leaf appearance, leaf growth, leaf nitrogen economy and photosynthetic capacity in maize (Zea mays L.). Field Crop Research, 93:64-73.

Witt C, Pasuquin JMCA, Mutters R \& Buresh RJ (2005) New leaf color chart for effective nitrogen management in rice. Better Crops, 89:36-39.

Wu J, Wang D, Rosen CJ \& Bauer ME (2007) Comparison of petiole nitrate concentrations, SPAD chlorophyll readings, and QuickBird satellite imagery in detecting nitrogen status of potato canopies. Field Crops Research, 101:96-103.

Yadava UL (1986) A rapid and nondestructive method to determine chlorophyll in intact leaves. HortScience, 21:1449-1450. 